\title{
Review of Silicon-Based Materials For Cellulosic Fabrics With Functional Applications
}

\author{
Amina L. Mohamed" and Ahmed G. Hassabo \\ National Research Centre (Scopus affiliation ID 60014618), Textile Industries Research \\ Division, Pre-treatment and Finishing of Cellulose based Textiles Department, 33-El- \\ Behouth st., (former El-Tahrir str.), Dokki, P.O. 12622, Giza, Egypt
}

\begin{abstract}
GILICONE has reached our lives in various ways, and in various forms one can find silicone. We are used for textiles in clothing and industry. As in the case of adhesives, binding additives, fabric coatings, dress lining and thread sealers, elastomers and rubbers are used. While for textile finishes, fiber lubricants and process supports, oils and emulsions are used. The overall challenge for "silicon materials treated textiles" is to enhance its properties. Many experimental tests were used to analysing the silicone effects on clothing, comparing to those treated with another materials for the same purpose. Treatment with silicone compounds provide that, silicone compounds impart new important properties to cellulosic fabrics. Consumers benefit from textiles based on silicone as it offers long-lasting comfort and efficiency. In contrast, silicone manufacturing is also worthy of meeting the tough challenges of industry. Now, if you go to buy jeans, you can be sure to find denim that will give you the impression of utter warmth and shape, that's how silicone affects textiles. Since use of silicone in textiles is generally important, there is still much potential to development a new silicone compounds or their mixture to improve or impart functional properties to textile materials. In any case, the future searches are widely for textile treated silicone. There have even been proposed possible uses in the therapeutic medical field.
\end{abstract}

Keywords: Silicon; Cellulose; Functional applications; Textile Industry

\section{Introduction}

In the periodic table, silicon is the fourteenth element. Despite the fact that it normally does not occur in free form, it represents about 25 percent of the outside layer of the world in its joined shape. Silicone compounds are intelligent materials in their extensive variety of valuable applications as far as chemistry science is concerned. The combination of silicon with organic compounds gives special properties that function over a wide temperature that decreases sensitivity to the temperature of materials based on silicone compared to other organic surfactants. These properties can be due to the Si-O bond's performance, mobility and adaptability, fractional ionic nature, and low interaction forces between non-polar methyl groups, qualities specifically identified with the relatively long $\mathrm{Si}-\mathrm{O}$ and $\mathrm{Si}-\mathrm{C}$ bonds. Similarly, the $\mathrm{Si}-\mathrm{O}$ and $\mathrm{Si}-\mathrm{C}$ size provides a peculiar rotational mobility that enables the atoms to obtain the minimal energy structure at interfaces, providing a significantly lower surface pressure than the organic polymers. The mistake for silicon with silicone is one of the most basic technical errors made by individuals relating to materials. The first "silicon" is used to refer to the basic material, $(\mathrm{Si})$; the second (silicone) to refer to oxygen-attached silicon ( $\mathrm{Si}-\mathrm{O})$ materials. Silicon is the most fundamental element from which to explore the origin in all silicone chemistry. Since it is not found in the metallic form in nature, quartz silicon is the initial phase in the chemistry. [1]

In the textile industry, silicone technology has brought a revolution as it plays an important role in the garment production process. The new age of silicone innovation discovery helps apparel manufacturers to produce practical fabrics, high-

"Corresponding Author: alo.mohamed12@hotmail.com

DOI: $10.21608 /$ JTCPS.2019.18580.1030

C2019 National Information and Documentation Centre (NIDOC) 
performance fabrics, and smart textiles that can satisfy consumer demands. Silicones have some useful features such as heat resistance, sunlight resistance, moisture, chemicals, and age. Most of them are used in sealants, adhesives, lubricants, medical applications, utensils for cooking, and insulation. It also found a place in the textile industry. The world's textile manufacturers can produce customized fabrics and clothing with the help of silicone technology that perfectly complements the functional needs of modern lifestyle. Whether the consumer is fashionable, comfortable, or budget-conscious, silicone technology helps textile manufacturers develop functional fabrics and high-performance textiles.

Silicon Chemistry and Nomenclature

The primary chain unit in polydimethylsiloxane (PDMS, -( $\left.\mathrm{SiMe}_{2} \mathrm{O}\right)-$ ) is abbreviated regularly to the letter D since the silicon molecule is connected with two oxygen atoms, this unit is prepared to expand in two headings through the polymer. Similarly, units M, T and Q can be defined as shown in Figure 1: [2]

The above polymer can be described as $\mathrm{MD}_{\mathrm{n}} \mathrm{M}$, which allows the description of various structures such as $\left(\mathrm{Me}_{3} \mathrm{SiO}\right)_{4} \mathrm{Si}$ or tetrakis(trimethylsilyloxy) silane, progressing towards $\mathrm{M}_{4} \mathrm{Q}$. Occasionally, superscripts are used to show assemblies other than methyl (e.g., $\mathrm{D}_{\mathrm{H}}$ for $\mathrm{HMeSiO}_{2 / 2}$ ). There are three types of composition of silicone polymers, as shown in Figure 2.

The production of siloxanes has been explain somewhere else. [2, 3] In synopsis, PDMS is acquired from the hydrolysis of dimethyldichlorosilane $\mathrm{Me}_{2} \mathrm{SiCl}_{2}$, which prompts a mixture of cyclic and linear oligomers:<smiles>CO[Si](C)(OCO[Si](C)(C)OCO[Si](C)(C)O[Na])OCO[Si](OC)(OC)OC</smiles>

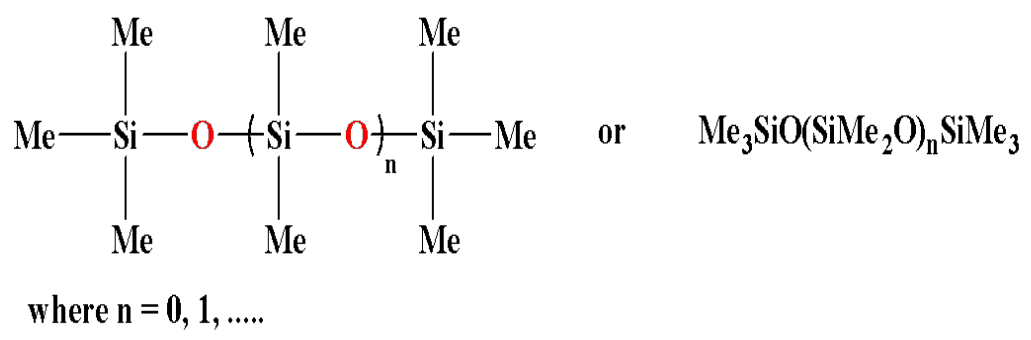

\footnotetext{
"M unit" is mono-substituted (one oxygen atom on silicon)

"D unit" is di-substituted (two oxygen atoms on silicon)

"T unit" is tri-substituted (three oxygen atoms on silicon)

"Q unit" is tetra-substituted (four oxygen atoms on silicon)

If organo-functional groups other than carbon are presented, the group is given a “*” after M, D, T or Q unit.
}

Fig.1: The primary chain unit in polydimethylsiloxan 


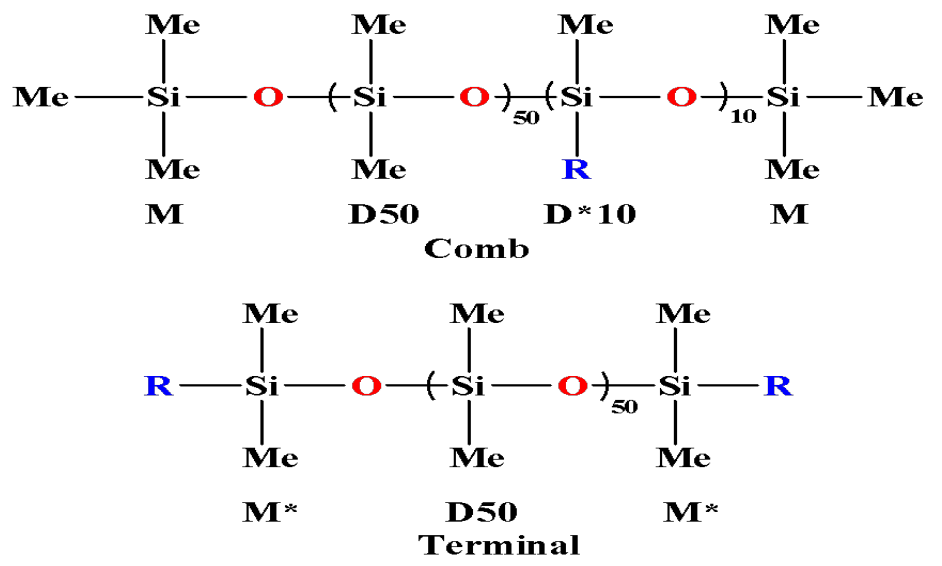

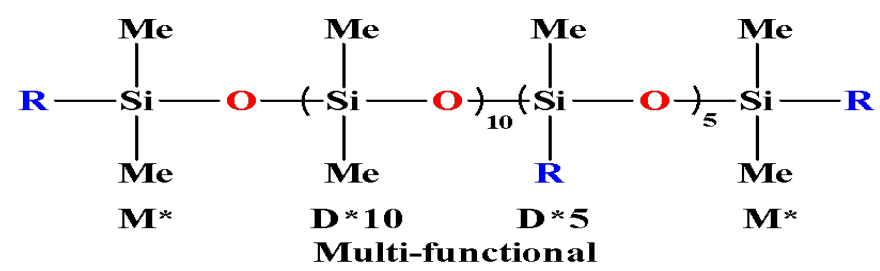

Fig. 2: Chemical composition of silicone polymers

$$
\begin{aligned}
& \times \mathrm{Me}_{2} \mathrm{SiCl}_{2} \underset{-\mathrm{HCl}}{\stackrel{\mathrm{H}_{2} \mathrm{O}}{\longrightarrow}} \times \underset{\text { disilanol }}{\mathrm{Me}_{2} \mathrm{Si}(\mathrm{OH})_{2}} \underset{-\mathrm{H}_{2} \mathrm{O}}{\longrightarrow} \underset{\text { linear }}{\mathrm{HO}\left(\mathrm{Me}_{2} \mathrm{SiO}\right)_{\mathrm{n}} \mathrm{H}}+\underset{\text { cyclic }}{\mathrm{z}} \underset{\left(\mathrm{Me}_{2} \mathrm{SiO}\right)_{\mathrm{m}}}{\longrightarrow} \\
& \text { Equ. (1) } \\
& n=20-50 \quad m=3,4,5, \ldots . .
\end{aligned}
$$

Higher molecular weight PDMS is acquired after polymerisation, e.g. hexamethyldisiloxane catalyzed by a strong acid or base as follow: may increase the material's low hydrophobicity and thermal stability, while other groups may behave biocidal or have an effect on molecular incorporation after use. Use organosilanes as

\section{$\mathrm{Me}_{3} \mathrm{SiOSiMe}_{3}+\mathrm{x}\left(\mathrm{Me}_{2} \mathrm{SiO}\right)_{4} \stackrel{\text { cat }}{\longrightarrow} \mathrm{Me}_{3} \mathrm{SiO}\left(\mathrm{Me}_{2} \mathrm{SiO}_{\mathrm{n}} \mathrm{SiMe}_{3}\right.$}

Classification of Silicon compounds Inorganic silicon compounds

Silicon is the second most plenteous element on the earth after oxygen. Silicon is found as silicate minerals (salts or esters of silicic acid). Sol-gel technique using silicic acid esters and the gel formation of can be occurred into two steps; (a) form silanol groups via hydrolyzed using water molecules and (b) condensate the silanol groups to form a polysilicic acid and form a silicon dioxide (see Fig. 3). [4]

\section{Organic silicon compounds}

In contrast to the inorganic silicon compounds, different organic groups attached to the silicon may change their properties. [4] Methyl groups
Equ. (2) precursors, tetraalkoxysilanes can be used in solgel techniques. These compounds contain up to three alkoxy groups attached to silicon and one to three organo-utilitarian groups, capable of building gel hydrophobicity or forming covalent bonds to various constituents. Organo-silanes are used in various applications, such as adhesion and/ or modification of the surface. [4] Chlorosilans are a class of reactive silicon compounds other than alkoxy silans. Methylchlorosilanes detected hydrophobic character in organic material during the preparation of methylchlorosilanes in a laboratory. $\mathrm{HCl}$ is discharged by hydrolyzing chlorosilans, which is the major disadvantage of this process. 
<smiles>CCOC(=O)NCCO[Si](OCC)(OCC)OCC</smiles>

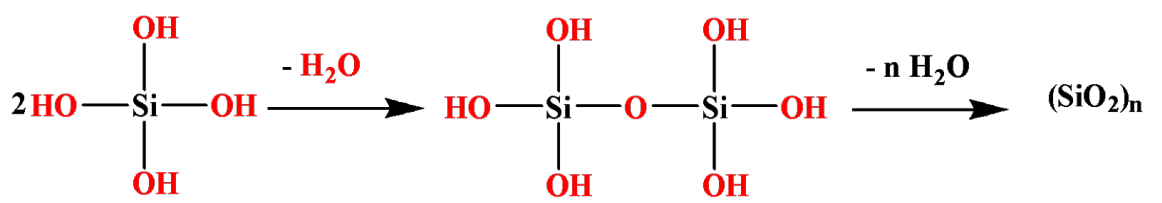

Fig.3: Mechanism of the sol-gel prepare [4]

The silicones are another class of organosilicon compounds. These are polymeric materials that are attached to silicon with a silicon-oxygen chain and hydrocarbon radicals. The word silicone is taken from the term silicon ketone, so the general equation for silicones $\left(\mathrm{R}_{2} \mathrm{SiO}\right)_{n}$ is like ketones $\left(\mathrm{R}_{2} \mathrm{CO}\right)$. In addition, the silicone repeat unit is "siloxane," while the most commonly used silicones are polydimethylsiloxanes (PDMS) (Figure 4). PDMS is a class of polymers ranging from fluids to elastomers, based on the chain length and the appended functionalities.<smiles>C[Si](C)(C)O[Si](C)(C)O[Si](C)(C)C</smiles>

Fig. 4: Chemical structure polydimethylsiloxane (PDMS).

\section{Classification of Silicones Compounds}

Silicones for textile might be classified into three types:

a. Reactive Silicone Polymers

- Methyl terminal methyl hydrogen polysiloxane

- Hydroxylterminalpolydimethylsiloxane.

- Alkoxy terminal polydimethylsiloxane.

- Epoxy modified silicones compounds

b. Non-Reactive Silicone Polymers

c. Organo Functional Silicone Polymers

- Amino modified silicones compounds

- Polyether modified silicones compounds

Classification of Silicones Compounds for Textile Finishing Application

Silicone utilized in textile could be classified into the following categories:

a. Silicone fluids b. Reactive silicone fluids

c. Functional silicones

d. Functional Reactive silicones

e. Mixed silicones

Silicone fluids

Silicone fluids are basically dimethylpolysiloxane, its chemical structure are illustrated in Figure 5. It was used for modification the surface of cellulosic fabrics to improve its properties such as hydrophilicity, soft handle and mechanical properties.<smiles>C[Si](C)(C)O[Si](C)(C)O[Si](C)(C)O[Si](C)(C)C</smiles>

Fig. 5: chemical structure of dimethyl polysiloxane

They were not exceptionally productive in improving surface properties. Silicone fluids are utilized as a primary auxiliary in the finishing fabric bath. The significant limitation of these materials is requirement for higher concentration and curing/setting temperatures (which mean high cost) to guarantee the required uptake.

\section{Reactive silicone fluids}

Emulsions of reactive silicones are assuming an expanding part in formulation innovation for water-borne system. Essential applications for silicone emulsions are in automotive polishes, textile finishing and coating. Silanol fluids are steady under normal conditions and have nonionic emulsifiers.

Aminoalkylalkoxysiloxanes with cationic emulsifiers are the best offered materials. PDMS with reactive groups (terminal or on the siliconoxygen backbone). There are two types of reactive groups are regularly utilized in textile industry. These types are: 
- Hydroxyl (-OH) groups at the end silicone compounds, generally knows in the industry as "Silanols".

- Hydride (Si-H) groups bonded to the silicone backbone, and usually known as $\mathrm{Si}-\mathrm{H}$ fluids, and its utilized to impart hydrophobic properties to the surface.

Chemical structure of silan and silanol compounds are illustrated in Figure 6.<smiles>[1H]</smiles>

Silane<smiles>CO[Si](C)(OC)O[Si](C)(C)O[Si]1(C)O[IH]O[Si](C)(OC)O1</smiles>
Bridged
icinal) Silano
Lone (acidic)

Silanol<smiles>CO[Si](C)(O)O[Si](C)(C)O[Si](O)(O)OC</smiles>

Geminal Silanol

Fig. 6: Chemical structure of silane and silanol compounds

These compounds are promptly show selfcondensation in the presence of organometallic catalyst, which lead to high molecular weight silicone polymer and impart permanent elastomeric properties to the surface. Reaction of these compounds with silanes lead to cross-linked network covered the surface.

\section{Functional silicones}

Functional silicones are depend on PDMS (polydimethylsiloxane) backbone and are modified to have functional groups to binding with the surface. In addition, amino or polyalkoxy have the same function like PDMS.

These function $\mathrm{s}$ include amino $\left(-\mathrm{RNH}_{2}\right)$, carboxyl (-COOH), epoxy $\left(\mathrm{CH}_{2} \mathrm{CHO}\right)$ or polyalkoxy $(\mathrm{EO} / \mathrm{PO})$. The following formula represents this category of molecules:
Amino silicones are the most broadly utilized silicones in textile applications to achieve a permenat softness to textile fabric. Carboxysilicones are used to impart a silky hand to the fabric surface. These silicones additionally can be utilized in conjunction with different silicones as a feel enhancer. It can be utilized in relation with silanol, epoxy and amino silicones fluids. Epoxysilicones confer a soft hand to different textile materials. It assumes an essential part in giving the crease recovery and enhanced tear strength. Therefore, it is offer one of the best surface property improvement.

\section{Functional Reactive silicones}

This is the most important class of silicone materials, which have combination of some properties together in the same compounds. In<smiles>[R]CCC[Si](C)(O[Si](C)(C)C)O[Si](C)(C)O[Si](C)(C)C</smiles>

Fig. 7: Chemical structure of functional silicones compounds. 
this way, this class of materials can offer softness, hydrophilicity and elastomeric properties to the treated fabrics. In this class, two types of materials are included:

- Amino silicones with terminal silanol or alkoxy groups

- Amino silicones with poly-ethoxylates.

These compounds guarantee a successful silicone distribution and good sorption because of presence of amino groups. These compounds are applied in macro or micro emulsion form to textile materials in presence of nonylphenylethoxylates or laurylalcoholethoxylates.

\section{Mixed silicones}

Mixed silicone compounds are silicones with various functionalities, reactivates and molecular weight. The mixing improve many properties which can't be develop with one silicone compounds, for example:

- Mixing a silicone compounds with high amino, low viscosity with low amino, high viscosity

- Mixing of amino silicones with ethoxylated silicones

Such mixes offer interesting hydrophilicity, soft handle, antistatic and tear-resistance properties.

Role of Silicon in Textile Industry

Siloxane compounds with hydroxyl or dimethyl groups are important for textile applications such as:

- Spinnerets lubricants in Synthetic fibre production

- $\quad$ spinning aids for fiber finishes

- Yarn finishing agents

- De-foaming agent in coloring and finishing processes

- Finishing agent for textile

- Silicone rubber for roller covers

Polysiloxanes are presence in oil form and they utilize through two methods:

a. using solvent

b. using oil in water-emulsion

Because of its wide range of use to various textile silicones have proved to be an excellent tool in the hands of finishers. Silicones offer to the textile the accompanying points of interest:
- Enhanced full and fresh handle

- Permanent water repellency

- Better clearness of shading and color

- Resistance to water and oil

- Enhancing in physical properties such as

a. Better sewability of garments

b. Improve the abrasion resistance

c. Improve the tear strength

d. Enhance the crease recovery angle

Applications of Silicone in textiles fields

In the textile industry, variations of silicone products are used. These include polydimethylsiloxanes, amido, functional amino silicones, silicones of methyl hydrogen, functional silicones of epoxy, hydroxy silicones, polyethers of silicone, and silicones of epoxy polyether. [5-14] Polydimethylsiloxanes are the most widely recognized silicone repellents. It have a special structure, which gives the ability to form hydrogen bonds and shows repellency consequences for the external fibre surface. It was intended to be permanent finishes contain a silanol and/or silan groups. The silanol and silan groups were react in order to form a 3D cross-linked sheath around fibres. Silicon repellent agents offer a high level of water repellency at moderately low concentrations. However, their repellency can be decreased if overabundance sums are applied. They are durable against washing, cleaning and soil repellency. Silicone repellent agents can be applied using either exhaustion or pad-dry-cure methods.

Silicone Compounds as Antibacterial Agents

Silicon based antibacterial agents (siloxane sulfopropylbetaine) with a reactive alkoxysilane group have been effectively prepared from diethoxymethylsilane, $\mathrm{N}$-dimethylallylamine and 1, 3-propanesultone. It contains both quaternary ammonium and reactive siloxane groups. Due to their ability to react with covalent bound onto the cellulose surface through finishing step. It have been utilized to confer antibacterial property to cotton fabrics. Antibacterial, hydrophilic, mechanical and thermal properties of the treated cotton fabrics have been investigated systematically and the result demonstrate that breaking strength and hydrophilicity have been extraordinarily enhanced. Then again, treated cotton fabrics provide great antibacterial activities against both gram negative and gram positive microbes. Likewise, they demonstrate no toxicity to animals and skin stimulation. [15, 
16] 3-mercaptopropyltriethoxysilane have been utilized to achieve whereby strong antibacterial properties, in which, it have been used to introduce thiol-reactive groups to cotton fabrics through a condensation reaction by the reaction of the ethoxy end group of the silicone compound and hydroxyl group of the cotton surface. At that point, the thiol functionalzed cotton fabrics have been reacted with the epoxy group of the quaternary ammonium salts of glycidyltrimethylammonium chloride form a chemical bond through thiol-epoxy click reaction. Many analytical techniques have been utilized to provide the reaction, for example, FTIR and SEM examination. Dyeing performance, Mechanical, antibacterial and washing properties of the treated fabrics have been evaluated. The results provide the formation of chemical bond between silanized cotton and the epoxy group of quaternary ammonium salt prompted imparting permanent antibacterial properties of treated cotton fabrics. [17]

N-halamine compounds have additionally much interest as an antimicrobial materials, because of their most ideal qualities, they are rechargeable, non-poisonous to human and they have antimicrobial properties against a few microorganisms. [18, 19] Therefore, different N-halamine siloxane have been successfully prepared, such as 4-(3-triethoxy silylpropoxyl) 2,2,6,6- tetramethyl pipridine, 5,5-dimethyl3(3-triethoxy silyl propyl) hydanation, 3-triethyl silylpropyl 1-2,2,5,5- teramethylimidazolidine and 3-(3-triethoxysilylpropyl) 7,7,9,9 tetramethyl- 1,3,8 - triazaspiro decane - 2,4dione. [20-26] These compounds have been used to produce antimicrobial cotton fabrics, and they were efficient antimicrobial agents against a wide spectrum of microorganisms. Chen et al [27] have been present an effective polymeric $\mathrm{N}$ - halamine siloxane onto cotton surface as a permnant antimicrobial agent, this compound have been prepared through a hydrosilylation reaction of poly(methyl hydosiloxane) and tertbutyl acrylate. Tethering siloxane monomer have been copolymerized with acrylamide to prepare another copolymer for treatment cotton surface to enhance the antibacterial properties against both Gram-negative and Gram-positive microbes. [28] All helamine siloxane compound could be covalently reinforced onto the surface of cellulose-based materials. Most of helamine siloxane compounds are water insoluble, which makes them not ideal application in industry. [29]
Polymerization of vinyl N-halamine acrylamide monomer with silane containing monomers have been occurred and the alkoxy groups were hydrolyzed and then reacted with cotton fibers via formation of silylether bonding. Chlorination process give the cotton fabrics a good antibacterial activity. [25, 30] Because of their significance, quaternary ammonium salts have been generally utilized for treated many textile materials. [29, 31] Polar and nonpolar interaction are the suitable interaction mechanism, which could be occurred between microbes and quaternary ammonium salts. Firstly, the polar interaction could be happen through cationic ammonium group of the quaternary ammonium salts, which attack the negative charge of cell membrane of the organisms. Moreover hydropobic chain of the quaternary ammonium compound have a non-polar interaction with the cell itself, the hydrophobic groups cause an interference of all key cell work by means of penetration into the microorganism cell. Therefore, increasing the carbon atom of the alkyl chain of the quaternary ammonium salt cause increasing the antibacterial activity of the finishing agent. Due to the polar interaction, silicon compound formed a complex with microbe, which subsequently interfere with all the proteins activity incorporating the important functions in the cell membrane of the bacteria. [29, 32] Polymeric quaternary ammonium salts containing siloxane have been prepared through reacting of polysiloxane having chlorohydrocarbon with tertiary amine, [33] the resultant polysiloxane have been applied to cellulosic fabrics and demonstrated an excellent antibacterial activity. [34]

Quaternary ammonium salts containing siloxane group have been utilized as a part of based fabrics by means of covalent bonds and it can't be absorbed into the body through reaching of the treated fabrics and the skin. Along these lines, it consider as antibacterial agent and it has been utilized as a part of modern applications for many years ago. [35] Quaternary ammonium nanoparticles having 3-(trimethoxysilyl)-propyl octadecyl-dimethyl ammonium chloride and sodium alginate have been prepared by ionic gelation with $99 \mathrm{~nm}$ particle size. Treated cellulosic fabrics with these nanoparticles demonstrated a good durability even after 30 washing cycles. [29, 36] Quaternary ammonium compound used also in the functionalization of polyhedral oligomeric silsesquioxanes (Q-POSS) and used as sol-gel precursors. octasilsesquioxanes, is 
one of the most regularly used POSS precursors which have cubic form with quaternary ammonium salt attached to silicon. It had been used to enhance the antibacterial properties of cotton fabrics. [37] Substitution of polycationic polysiloxanes (e.g. polydimethylsiloxane, polymethylhydrosiloxane) with a quaternary ammonium salt or imidazolium salt are imperative as bacteriostats on textile materials. [38-42] Impregnation of biocides in silica nano particles was additionally a method for give antimicrobial property to cotton fibres. Mahltig et al [43] has been explored the impact of silica covering embedded with various biocides, for example, cetyltrimethylammoniumbromide, octenidine and colloidal silver in which the silica sol solutions have been synthesized from tetraethoxysilane and 3-glycidyloxypropyltriethoxysilane and it affect the antibacterial property of cotton fabrics and exhibit high inhibition zone against the fungi Aspergillus niger. Alkoxy groups of alkoxysilanes were hydrolyzed and produce silanol groups, which condensed together or with hydroxyl groups of celolulosic fibres to form a covalent bond between $-\mathrm{SiOH}$ and $-\mathrm{OH}$ groups and cause increasing in the durability and washing resistant. $[37,43,44]$

\section{Silicone Compounds as Flame retardant Agents}

With an increase in temperature, a fire retardant agent is used to make products less flammable. Of starters, it operates through various strategies to absorb energy away from the fire or to remove the oxygen to reach the gas or fuel. Polymers for fire-resistant applications are interesting, and the silica nanoparticle is another form of fire-resistant nano-composite nanoparticles. A polymer's flame retardant behaviour is characterized by various procedures or variables, such as spread speeds, burning levels, combustion attributes, etc. One of the main characteristics of the fire retardant is the creation of char which produces a coating that hinders oxygen penetration and provides a protective layer between heat and gas. The best ingredients for shaping burn are phosphorus and silicone compounds. [11, 45]

Sol-gel derived silica coatings have been exploited to reduce the flammability of cotton fabrics. [46] Tetraethylorthosilicate (TEOS) has therefore been used as a precursor to silica coating. Thermal behaviour and fire resistance of the treatment fabrics have been enhanced. In addition, the coatings could decrease the heat release rate and increase the ignition time of fabrics. [47] On the other hand, various precursors for silica or other oxidise stages and parameters of the procedure are related to the morphology of coatings derived from sol-gel. The impact of temperature and time of thermal treatment and the precursor was fully explored in the first: water molar ratio on cotton fire retardance. [48] It was found, in particular, that significant improvements in cotton heat flux resistance were achieved by completing the sol-gel preparation at $80^{\circ} \mathrm{C}$ for 15 hours, keeping 1:1 water: tetramethylortosilicate (TMOS) molar ratio. [49] Depending on the length of alkoxy groups attached to silicon, tetramethylortosilicate (with four methoxyl groups) tetraethylorthosilicate (with four ethoxyl groups) and tetrabutylorthosilicate (with four butoxyl groups) is one of the important roles in reducing/increasing flame spread. Hence, it is shown that the higher the reduction in flame spread is the shorter alkoxy group. [50, 51]

In comparison, the number and type of hydrolysable groups attached to silicon indicate that: (i) alkoxysilans with a low number of hydrolysable groups (i.e., two or three) such as TEOS increase in smoke release and nature / morphology, (ii) replacement of an amino group (APTES) with an alkyl chain (TEES) promotes the production of a reduced and thinner residue and (iii) compounds with a high number of alkoxy functionalities, improve the flammability of the fabrics. [51] The use of aluminium isopropylate, tetraethylortho-zirconate and tetraethylorthotitanate as activating precursors of silica coating improves the efficiency of flame retardant. [52, 53] Coating with silica sol-gel with additional flame retardant materials including elements $\mathrm{P}$ or $\mathrm{P}$ with $\mathrm{N}$ provide the synergistic effects that enhance fire efficiency. For this purpose, three different ways can be accomplished: (i) using silane and phosphate bearing alkoxysilane, (ii) mixing an alkoxysilane with a source of phosphoric acid, or (iii) incorporating an alkoxysilane bearing silane and phosphate functionalities into compounds containing $\mathrm{P}$ and N. [53-55] Simultaneous presence of $\mathrm{P}$ and $\mathrm{Si}$ elements in the same formula, resulting in the formation of organic-inorganic hybrid coatings. Diethylphosphatoethyltriethoxysilane (DPTES), for example, was used to synthesize a hybrid organic-inorganic phosphorus-silicon coating. [53, 54] In addition, DPTES (P source) was initially combined with APTES (Si source) and melamine-based resin (M) (N source), increasing the yield of char combination. The N-source can 
also be replaced with $\mathrm{N}, \mathrm{N}, \mathrm{N}^{\prime}, \mathrm{N}^{\prime}, \mathrm{N}^{\prime}, \mathrm{N}^{\prime}, \mathrm{N}^{\prime}-$ hexakis-methoxymethyl-[1,3,5]triazine-2,4,6triamine (MF) and the relative proportions of DPTES and MF have been optimized. [55]

\section{Silicone Compounds as Water and Oil Proofing Agents}

Wenzel and Cassie-Baxter are the suggested template to explain how superhydrophobic surfaces can be constructed by (i) roughening the same through microstructures or nanostructures and/or ii) minimizing surface energy due to waxy materials embedded at the top of the structures. For example, a micro-processing approach for rough surface synthesis and consequent treatment with silane or fluorine-containing polymers to minimize surface heat. Roughened surfaces are usually prepared by putting nano-sized particles on the substrate using sol-gel technique and are particularly suitable for fabric, glass and paper applications. [56] Sol-gel methods of fluoroalkylsilanes combined with other silane compounds used to have a co-condensate in many work. In these nano-composites, inorganic and organic networks are covalently connected and homogeneously combined at the nanometre scale, which improve the mechanical properties of treated materials. It also provides an outstanding adhesion of the coatings on various substrates such as fabric, glass and polymers. Use organically modified alkoxysilans containing aliphatic or heavily fluorinated groups in the long chain, solgel provides broad potential for manufacturing water and oil repellent fabrics. [56, 57]

A highly hydrophobic and oil-repellent cotton cloth by sol-gel procedures through a one-stage application of altered silica-based coatings. In the middle of the acid catalysed hydrolysis of TEOS or fluorinated alkoxysilans, which can advance the silane adsorption to the $\mathrm{OH}$ of the cellulose structure by hydrogen bonding. Sol-gel's use of a fluorinated alkoxysilane on cotton fabrics is a promising method for fabric finishing to offer enduring hydro and oil repellence. In addition, using water and oil measurements, a good contact angles and lower absorption time values were obtained on treated cotton. [58] Another process for preparing super hydrophobic cotton surfaces was tested on epoxy-functionalized cotton textiles through complex coating of amino and epoxy functionalized silica nanoparticles (SiNPs). This approach developed a surface roughness of two dimensions, followed by stearic acid hydrophobization. In addition, the interaction between fibre and silica coating is improved. The resultant coating demonstrated robust cellulosic layer superhydrophobicity. $[36,59]$ Another process was used to prepare superhydrophobic cellulose surfaces by chemical vapour deposition followed by hydrolyzation and polymerization. [60] The initial step of this process is to expose cotton to a saturated atmosphere with trichloromethylsilane, and then to hydrolyze the remaining $\mathrm{Si}-\mathrm{Cl}$ bonds, the cloth has been immersed in an aqueous pyridine solution. Eventually, the resulting application layer does not have any changes in colour and/or morphology after drying at $150^{\circ} \mathrm{C}$ for 10 minutes. [36] The co-hydrolysis and polycondensation of a mixture of three different silicon compounds (hexadecyltrimethoxysilane, tetraethoxyorthosilcate and 3-glycidoxypropyltrimethoxysilane) was used to create a clear and robust superhydrophobic substrate. [61, 62] Natural fluoroalkyl-functional waterborne siloxane, nanosize silver particles and reactive organic-inorganic binder have been prepared for water and oil repelling finishes for cotton fibers and provide strong water and oil repelling properties. [63] For cotton fabrics, perfluorooctyltriethoxysilane was used to prepare a hydrophobic and oleophobic sol-gel coating with a long antibacterial effect. [64] Liang et al developed a TiO @ $@$ fabric composite using a onepot hydrothermal reaction on the cotton layer to achieve high oil-water repellence. From that point on, an efficient superhydrophobic $\mathrm{TiO}_{2} @$ fabric was developed by fluoroalkylsilane modification for the application of oil-water repellence. An extremely high superhydrophobicity was imparted to the treated material. [65]

\section{Silicone Compounds as Softening Agents}

Silicone softeners enhance the products to give a silk soft hand, great lubricity, tear strength, abrasion resistance and good crease recovery and so on. Silicone softeners are more costly than fatty softeners. It demonstrates incredible durability and temperature stability. $[66,67]$ Because of the specific properties of silicone compounds, and additionally their higher adequacy comparing to normal auxiliaries, silicone-based finishing agents for textile industry have a significant important. The most imparted properties to textile fabrics depending on its adaptability of backbone and low surface energy are:

1. highly decreasing in fiber friction which impart the soft hand to fiber and fabric and 
2. hydrophobic fiber surface prompting water repellency up to extremely high level.

Silicone have many applications in the textile industries including different silicone compounds such as polydimethylsiloxanes, amido, amino functional silicones, methyl hydrogen silicones, and epoxy functional silicones, hydroxy practical silicones, silicone polyethers and epoxy polyether silicones. [5, 6] Silicone softener has high impact on increasing the soft hand feel of cotton fabrics, silicone softener gives water repellent property to the materials. Such water repellency is given by methyl groups, which are arranged and appended to the fiber surface by silicone bond. [68] Wrinkling of the cotton fabrics is depending on the chemical properties of the fibers. Wrinkle resistance is gotten by easy care finishing. [66] Silicone oils have a very important role in textile finishing. Many important requirements like improving the softness, hydrophobicity, whiteness, fastness. The advancement of silicone softener is still under investigation. In the textiles, silicones are applied from various conveyance frameworks to give different advantages like lubricating, softening, foam control or hydrophobic coatings. [1] A hydrophobic finish was one of the main uses for silicones on cotton fabrics. Coincidentally, this effect was noticed in a pilot plant for the manufacture of dimethyldichlorosilane, where it was noted that towels and paper were more hydrophobic. There are two types of silicone softeners used in fabric finishing at the moment.

\section{Methyl oils}

In fabric softening applications, methyl oils (polydimethylsiloxanes) are first used. For example, shiny surface tastes and a novel soft handle made them quickly popular. The possibility of crosslinking Si-OH or Si-OR ending species on the texture to acquire interpenetrative networks and elastomeric impacts is a very fascinating element. Methyl oils are used in the pigment printing method as sewing thread lubricants to promote soft hand and rubbing speed. For the processing of fibers used in pillow fillings, crosslinkable organisms are used.

\section{Amino oils}

Amino oils (amino-utilitarian organopolysiloxanes or aminosilicones) are the silicone class that naturally dominates the current market of softeners. This is related to their good soft-handle quality. Aminopropyl and aminoethylaminopropyl-silicones are the most well known products of this softener class. The characteristics of the softeners can be modified in different ways, including:

- Useful groups

- Molecular weight (described by oil viscosity), regulated primarily by $\mathrm{x}$; calculation of substituted groups, y (amine number); distribution of substituted groups in the chain; chain end $\mathrm{X}$, which may be reactive / cross-linkable ( $\mathrm{X}=\mathrm{OH}$ or $\mathrm{OR})$ or end $(\mathrm{X}=\mathrm{Me})$.

\section{Chemical character of the functional group}

Homopolymers of dimethylsiloxane show exceptionally weak softener performance and hardly affect fiber wettability. The purpose behind this activity is weak fiber contact and consequently uneven surface dispersion. Epoxy-silicones are stronger softeners than dimethylsiloxanes due to polar interactions between polymer side chains and cellulose and giving observable hydrophobic effects. Amino-silicones are better than epoxysilicones, most likely due to a significantly improved orientation and superior fiber surface distribution due to strong dipole-dipole hydrogen bonding and electrostatic fiber interactions, especially with cellulosic materials. In this way, it is possible to continuously represent the treated fabric. The result is low fiber friction and a hydrophobic surface. Aminoethylaminopropyl and cyclohexylamino silicones with similar structures have a similar softening effect. Textile materials treated with cyclohexylaminosilicones are more hydrophilic in light of weaker fiber interactions. As a standard, aminoethylaminopropylsilicones appear to be better than other known useful silicones containing amino groups (counting aminopropyl) or amine subordinates (for example, amido groups) in terms of imparting softness to the fabric, most likely due to the connection between amino groups located nearby. In making fabric softness, silicones with primary amino groups are more effective than those with secondary amino groups or amine derivatives. Molecular simulations have recently confirmed this experimental finding and it is concluded that secondary amino groups are not as effective in increasing the attractive interaction (and therefore softening) compared to primary amino groups.

\section{Testing and evaluation of Silicon incorporated textiles}

Most widely used analytical methods for organic materials can also be extended to silicones. The analytical methods applicable to the identification and characterization of silicones 
have been clarified in many publications. [1] Fourier transform infrared spectroscopy (FT-IR) is generally accessible and makes the detection of silicon on the fabric substrate by a simple process. Silicones have 1260, 1100-1000 and $770 \mathrm{~cm}^{-1}$ bands of absorption, which ensures the amounts can be differentiated as low as 1 percent. This method can discriminate between polydimethylsiloxane, groups of trimethylsilyloxy and products of copolymer. For the identification of silicones adsorbed on a surface, other infraredbased methods such as FT-IR/ATR or FT-IR/ DRIFT are particularly used. As a norm, the silicone coating at the surface's highest point is thin and is a distinctive signature of the surface's bulk. Notwithstanding infrared techniques, atomic attractive reverberation spectroscopy (NMR) can be used to acquire polymer structural information ${ }^{1} \mathrm{H},{ }^{13} \mathrm{C}$ and ${ }^{28} \mathrm{Si}$ NMR recognizes data such as methyl, vinyl, phenyl or polyester groups on the form of organic substituents on the silicone skeleton and discern the degree of substitution in these polymers. X-ray photoelectron spectroscopy (XPS) and time of flight-secondary ion mass spectrometry (TOF-SIMS) are more complex techniques for detecting and characterizing silicones within the 10-50 $\AA$ surface range. [62, 69, 70]

Confocal Raman Microscopy (CRM) is commonly used as an add-on to other molecular spectroscopy methods, such as UV-vis, FTIR, and NMR. Exploring these dispersions inside polymers is particularly suitable. [71] Nevertheless, the interpretation of the Raman profile information is intertwined with the air / sample interface refractive impacts. [72-74] A range of Confocal Raman Microscopy provides data on normal vibration modes within a sample for their chemical groups. Raman spectroscopy is particularly profitable for the identification of natural and synthetic fibers such as cotton, linen, polyester and nylon. [75-79] Gel permeation chromatography (GPC) using a refractive index detector helps one to obtain midpoints of molecular weight and data about appropriation. Nevertheless, often the residual Si-H levels are too small for analysis to be taken into account (e.g., as after a hydrosilylation response). A more effective approach here is gas chromatography paired with a thermal conductivity detector (GCTCD). This technique works indirectly when the sample is hydrolyzed in the presence of a base as a catalyst to analyze the hydrogen produced.

\section{Toxicology of silicones compounds}

Silicones are used as part of a wide range of uses. Such silicones contain linear and/or cyclic reactive oligomers with low molecular weight and/ or methyl siloxanes and/or polydimethylsiloxane (PDMS) polymers with viscosities from 10 to 100,000 or above. [1]

Volatile methyl siloxanes (VMS) like cyclic siloxanes, $\left(\mathrm{SiMe}_{2} \mathrm{O}\right)_{n}$, are generally utilized as a part of healthy skin, specifically four and five cyclics ( $\mathrm{n}=4$ and 5) referred to D4 and D5, respectively. Safety studies conducted on D4 and D5 have demonstrated impacts and proved that this no hazard to human health. [80] D4 and D5 cause a non-unfavorable, versatile increment in liver weight, which considered phenobarbitallike. [81, 82] Other materials are genotoxic or mutagenic nor are they immunotoxic. [80] Ordinarily, D4 and D5 appear around $0.5 \%$ and $0.05 \%$ dermal assimilation, respectively. Taking after dermal retention, more than $80 \%$ of D4 and $90 \%$ of D5 is wiped out in expired air through 24 $\mathrm{h}$ of exposure. [83]

The lowest molecular weight of linear silicon material is the highly volatile unstable hexamethyldisiloxane $\left(\mathrm{Me}_{3} \mathrm{SiOSiMe}_{3}, \mathrm{HMDS}\right)$ which is not generally toxic. Nonetheless, recent data revealed an earlier outbreak of testicular and kidney tumors in male rats exposed by inhalation to high levels of pollution. Certain linear structure of three, four, or five siloxane silicone materials has not shown any dangers in the studies to date, but the data is minimal to long-term use. [84] By traditional penetration paths, the products have severely limited absorption. Higher molecular weight silicon polymers and linear PDMS materials with low molecular weight are not mutagenic, disruptive, or severely toxic. [84] Trimethylsililoxy end-blocked PDMS polymers $\left(\mathrm{Me}_{3} \mathrm{SiO}\left(\mathrm{SiMe}_{2} \mathrm{O}\right)_{n} \mathrm{SiMe}_{3}\right)$ with 10 to 100,000 viscosities are the most widely used silicones. Via standard ingestion channels, which are either oral or dermal, these substances have shown no toxicity. There is no suggestion of mutagenic or genotoxic effects in vitro. Repeated oral or dermal doses with varying viscosities did not have antagonistic effects on a variety of groups of mammalian species. There is no evidence from studies conducted with rats or rabbits of regenerative or teratogenic effects of PDMS. Generally speaking, this information shows no PDMS threat to men. 
Silicones Compounds and their Impact on the Environment

For the remainder of their life cycle, countless are guided to determine the fate and impacts of silicones in the world. Environmental discharges from polydimethylsiloxane (PDMS) products are fully controlled and should be approved by regulatory experts as far as possible. The environmental future of silicones depends on the way of use, the physical form of the material, and the distribution technique to a great extent along these lines. Low molecular weight PDMS polymers $(<1000 \mathrm{Da})$ are used as part of personal care products as well as household care. High molecular weight PDMS polymers are important for industrial and domestic use as antifoams and ointments. [85] In any case, a more imperative application is, for example, as a "solid" silicone, PDMS-based rubbers or sealants that can be used either at home (e.g., shower sealants, preparation of product or baby teats) or in a variety of industrial applications such as material or textile coatings, hardware, silicone moldings and elastic gaskets. These were changed back to inorganic materials, amorphous silica, carbon dioxide, and water vapour in some situations. "Solid" silicones, high and low molecular weights used for cleaning off products, such as shampoos, hair conditioners or silicone antifoams in cleaners, turn out to be a part of industrial sewage. The same applies to PDMS used in pharmaceuticals as an anti-flatulent. High molecular weight silicones are essentially insoluble in water, and are subsequently adequately expelled from civil wastewater into the sludge during wastewater treatment as a result of their high limiting potential for organic matter. Broad reviews show that more than 95 percent of silicones are expelled from effluent along these lines, and that focusing on released effluent limits recognition levels $(5 \mu \mathrm{g} / \mathrm{l})$. [86]

Practically no take-up into the plants has been seen, which is inevitable with creature thoughts revealing that high molecular weight PDMS is too big to go through either plant or animal organic movies. Wide analyses ranging from small-scale laboratory tests to field trials indicate that sewage-sludge bound PDMS is contaminated by interaction with clay minerals in soils. [87-89] Dimethylsilanediol, $\mathrm{Me}_{2} \mathrm{Si}(\mathrm{OH})_{2}$, is an important degradation material, paying no attention to the molecular weight of PDMS. [88] For coating, silicones have been commonly used. Silicones are provided as an emulsion or liquid. Even when treated with very low concentrations, silicones yield good performance. This very low concentration will ensure limited environmental and ecological effects. Polydimethyl siloxane (PDMS) is highly resistant to micro-organism bio-degradation, but under exceptionally strong degradation occurs. Catalyzed PDMS hydrolysis and oxidation result in low molecular weight (a) siloxanols and (b) sillanols being divided. PDMS is environmentally idle and has been found to have no effect on microscopic organisms that consume oxygen or are anaerobic. It does not hinder the cycle of biological treatment of sewage. There were no adverse effects for germination of seeds, survival rates or mass harvesting of plants. Nitratethe loss of nitrogen in the presence of liquid PDMS has not changed, which does not induce critical results in populations of microorganisms. There is no evidence that PDMS can inhibit in a few products the microscopic organisms that are responsible for nitrogen fixation. Silicon has a strong weaving and finishing usefulness. Since the textile industry dominates fluid operations, it is possible that silicones migrate by sewage, either from scouring processes or from bath finishes. Essentially, even after anaerobic assimilation, all silicone compounds are kept on the sludge. The silicone content of the sewage sludge returns amorphous silica. We decay chemically at the level where sludge is used as a switch in soil. This eventually changes back to normal substances, inorganic species of silicone, carbon dioxide, and water over the silicones.

\section{Safety and Precautions during Application}

Because most silicones are important to water-insoluble textile material finishing agents, emulsion is set up in an appropriate aqueous system. When choosing a suitable emulsifier, it should be noted that any product with high wetting and/or rewetting properties must be held a tactical distance from it as these operators continue to invalidate the water repellent qualities of the silicone finish. The cumulative emulsifier is the one that reduces cotton handling of silicones. The volume and size distribution of the emulsified molecules, temperature and the concentration of impurities are the factors of emulsion stability. Non-ionic emulsifier from the largest and fastestgrowing emulsifying agent classes. Some of the ingredients used to emulsify silicone oil are fatty alcohol polyethoxylates, octyl, nonyl phenol polyethoxylates. Mostly, silicone oil (30\% liquid emulsion oil) should be the emulsion of silicones used as softeners in the fabric. 
The relevant criteria for the use of silicone emulsion to be considered are:

- The cotton cloth to be manufactured shall be washed and shall not contain any residue from the coloring operations / processes.

- The cotton fabric should be made with the necessary quantity of silicone impregnated.

- After impregnation, the cloth should be dry and eventually acidic at elevated temperature so $\mathrm{pH}$.

Most of the organometallic salts of copper, tin and zirconium are used as catalysts to be added to the dye bath comprising the diluted silicone emulsion. Amino silicones were used as softening agents, along with their modified ones. We give a constant, comfortable hand and a small recovery angle raise. In the case of poly(methyl hydrogen sliloxane), the emulsion must not come into contact with alkali, as it causes the release of gaseous hydrogen, which is reasonable for a fire hazard. The jerry's highest point may contain the commercial emulsion of silicone must have a small gap to release any hydrogen that can be released through storage and maintain an explosion, or splashing the emulsion when the top of the jerry can be opened.

Advantages of Curing Silicones in Materials

- When completely cured, silicones give a lasting finish, they are ideal for developing a cross-linked device that joins the network of cotton fabrics.

- A 3D cross-linked silicone can be used to finish waterproof.

- Cross-related silicones provide a substantial degree to the cotton body / piece of clothing

- A soft and smooth touch is also imparted to the textile fabric layer

- Improvement in the quality of textile fabrics due to the cross-related composition of the fabric.

A superior modification of resilience and hydrophobic quality can be accomplished by selecting a suitable cross-linking site and a good catalyst for a silicone curable polymer.

\section{Conclusion}

Silicon and its using in textile industries have been discussed well during this review including silicone chemistry, nomenclature and their classification. Classification of silicone compounds to inorganic and organic compounds have been investigated and reported. In addition, classification of silicone compounds for textile finishing application including silicone fluid, reactive silicone fluid, functional silicone, functional silicone reactive and mixed silicones were explored and classified. Furthermore, the role of silicone and its application in the textile industry as an antibacterial, flame retardant, water and oil repellent and softeners Agents have been monitored. From another point of view, evaluation and analysis for silicone integrated textiles, toxicology of silicone products, impact on the environment, health precautions and advantages of silicone curing of materials were discussed and explained in the review.

\section{References}

1. Andriot, M., DeGroot, J.V., Meeks, R., Gerlach, E., Jungk, M., Wolf, A.T., S. Cray, T.E., Mountney, A., Leadley, S., Chao, S.H., Colas, A., Buyl, F.d., Dupont, A., Garaud, J.L., Gubbels, F., Lecomte, J.P., Lenoble, B., Stassen, S., Stevens, C., Thomas, $\mathrm{X}$. and Shearer, G., Silicones in Industrial Applications, in Silicon-Based Inorganic Polymers, R.D. Jaeger and M. Gleria, Editors Nova Science Publishers (2008)

2. Mark, Bikales, Overberger and Menges, Encyclopedia of Polymer Science and Engineering, in Journal of Polymer Science Part C: Polymer Letters, Wiley Subscription Services, Inc., A Wiley Company: New York. 835 (1987)

3. O'Lenick, A.J., Siltech, L.L.C. and Dacula, G., Basic Silicone Chemistry - a Review. Silicone Spectator "TM "electronic newsletters in the field of Silicone Chemistry, placed on the web four times a year" (2009)

4. Mai, C. and Militz, H., Modification of Wood with Silicon Compounds. Inorganic Silicon Compounds and Sol-Gel Systems: A Review. Wood Science and Technology, 37(5) 339-348 (2004)

5. Skinner, M.W., Qian, C., Grigoras, S., Halloran, D.J. and Zimmerman, B.L., Fundamental Aspects of Aminoalkyl Siloxane Softeners by Molecular Modeling and Experimental Methods. Textile Research Journal, 69(12) 935-943 (1999)

6. Vazquez, F., Silicone Softeners for Stain Repellent and Stain Release Fabric Finishing, Dow Corning Corporation, Greensboro, N.C. . 58 (2004)

J.Text.Color. Polym. Sci., Vol., No.(2019) 
7. Mohamed, A.L., El-Naggar, M.E., Shaheen, T.I. and Hassabo, A.G., Novel Nano Polymeric System Containing Biosynthesized Core Shell Silver/Silica Nanoparticles for Functionalization of Cellulosic Based Material. Microsystem Technologies, 22(5) 979-992 (2016)

8. El-Naggar, M.E., Hassabo, A.G., Mohamed, A.L. and Shaheen, T.I., Surface Modification of Sio2 Coated $\mathrm{ZnO}$ Nanoparticles for Multifunctional Cotton Fabrics. Journal of Colloid and Interface Science, 498 413-422 (2017)

9. Mohamed, A.L., Silan/Biopolymer Microgels for Functionalization of Cotton Fabric: Antibacterial and Dual Responsive $\mathrm{Ph}$ and Temperature. Journal of Applied Pharmaceutical Science, 7(7) 77-88 (2017)

10. Mohamed, A.L., El-Naggar, M.E., Shaheen, T.I. and Hassabo, A.G., Laminating of Chemically Modified Silan Based Nanosols for Advanced Functionalization of Cotton Textiles. International Journal of Biological Macromolecules, 95 429437 (2017)

11. Hassabo, A.G., Mohamed, A.L., Shaarawy, S. and Hebeish, A., Novel Micro-Composites Based on Phosphorylated Biopolymer/Polyethyleneimine/ Clay Mixture for Cotton Multi-Functionalities Performance. Bioscience Research, 15(3) 25682582 (2018)

12. Mohamed, A.L. and Hassabo, A.G., Composite Material Based on Pullulan/Silane/ZnO-Nps as $\mathrm{Ph}$, Thermo-Sensitive and Antibacterial Agent for Cellulosic Fabrics. Advances in Natural Science: Nanoscience and Nanotechnolgy, 9(4) 045005 (19) (2018)

13. Hassabo, A.G., El-Naggar, M.E., Mohamed, A.L. and Hebeish, A.A., Development of Multifunctional Modified Cotton Fabric with TriComponent Nanoparticles of Silver, Copper and Zinc Oxide. Carbohydrate Polymers, 210 144156 (2019)

14. Hassabo, A.G. and Mohamed, A.L., Novel Flame Retardant and Antibacterial Agent Containing Mgo Nps, Phosphorus, Nitrogen and Silicon Units for Functionalise Cotton Fabrics. Biointerface Research in Applied Chemistry, 9(5) 4272 - 4278 (2019)

15. Chen, S., Chen, S., Jiang, S., Mo, Y., Luo, J., Tang, J. and Ge, Z., Study of Zwitterionic Sulfopropylbetaine Containing Reactive Siloxanes for Application in Antibacterial Materials.

J.Text.Color. Polym. Sci., Vol., No. (2019)
Colloids and Surfaces, B: Biointerfaces, 85(2) 323-329 (2011).

16. Chen, S., Chen, S., Jiang, S., Xiong, M., Luo, J., Tang, J. and Ge, Z., Environmentally Friendly Antibacterial Cotton Textiles Finished with Siloxane Sulfopropylbetaine. ACS Applied Materials \& Interfaces, 3(4) 1154-62 (2011)

17. Yu, D., Xu, L., Hu, Y., Li, Y. and Wang, W., Durable Antibacterial Finishing of Cotton Fabric Based on Thiol-Epoxy Click Chemistry. RSC Advances, 7(31) 18838-18843 (2017)

18. Li, R., Hu, P., Ren, X., Worley, S.D. and Huang, T.S., Antimicrobial N-Halamine Modified Chitosan Films. Carbohydr Polym, 92(1) 534-9 (2013)

19. Dong, A., Lan, S., Huang, J., Wang, T., Zhao, T., Xiao, L., Wang, W., Zheng, X., Liu, F., Gao, G. and Chen, Y., Modifying Fe3o4-Functionalized Nanoparticles with N-Halamine and Their Magnetic/Antibacterial Properties. ACS Applied Materials \& Interfaces, 3(11) 4228-4235 (2011)

20. Barnes, K., Liang, J., Worley, S.D., Lee, J., Broughton, R.M. and Huang, T.S., Modification of Silica Gel, Cellulose, and Polyurethane with a Sterically Hinderedn-Halamine Moiety to Produce Antimicrobial Activity. Journal of Applied Polymer Science, 105(4) 2306-2313 (2007)

21. Barnes, K., Liang, J., Wu, R., Worley, S.D., Lee, J., Broughton, R.M. and Huang, T.S., Synthesis and Antimicrobial Applications of 5,5'-Ethylenebis[5Methyl-3-(3-Triethoxysilylpropyl)Hydantoin]. Biomaterials, 27(27) 4825-30 (2006)

22. Liang, J., Owens, J.R., Huang, T.S. and Worley, S.D., Biocidal Hydantoinylsiloxane Polymers. Iv.N-Halamine Siloxane-Functionalized Silica Gel. Journal of Applied Polymer Science, 101(5) 3448-3454 (2006)

23. Liang, J., Wu, R., Huang, T.S. and Worley, S.D., Polymerization of a Hydantoinylsiloxane on Particles of Silicon Dioxide to Produce a Biocidal Sand. Journal of Applied Polymer Science, 97(3) 1161-1166 (2005)

24. Ren, X., Kou, L., Liang, J., Worley, S.D., Tzou, Y.-M. and Huang, T.S., Antimicrobial Efficacy and Light Stability of N-Halamine Siloxanes Bound to Cotton. Cellulose, 15(4) 593-598 (2008)

25. Liang, J., Chen, Y., Barnes, K., Wu, R., Worley, S.D. and Huang, T.S., N-Halamine/Quat Siloxane Copolymers for Use in Biocidal Coatings. Biomaterials, 27(11) 2495-501 (2006) 
26. Liang, J., Wu, R., Wang, J.W., Barnes, K., Worley, S.D., Cho, U., Lee, J., Broughton, R.M. and Huang, T.S., N-Halamine Biocidal Coatings. Journal of Industrial Microbiology \& Biotechnology, 34(2) 157-63 (2007)

27. Chen, Y., Zhong, X.-s. and Zhang, Q., Synthesis of $\mathrm{Co}_{2}$-Philic Polysiloxane with N-Halamine Side Groups for Biocidal Coating on Cotton. Industrial \& Engineering Chemistry Research, 51(27) 92609265 (2012)

28. Kocer, H.B., Worley, S.D., Broughton, R.M. and Huang, T.S., A Novel N-Halamine Acrylamide Monomer and Its Copolymers for Antimicrobial Coatings. Reactive and Functional Polymers, 71(5) 561-568 (2011)

29. Ying, L., Ren, X. and Liang, J., Antibacterial Modification of Cellulosic Materials. BioResources, 10(1) 1964-1985 (2015)

30. Cerkez, I., Kocer, H.B., Worley, S.D., Broughton, R.M. and Huang, T.S., N-Halamine Copolymers for Biocidal Coatings. Reactive and Functional Polymers, 72(10) 673-679 (2012)

31. Liu, S. and Sun, G., Durable and Regenerable Biocidal Polymers: Acyclic N-Halamine Cotton Cellulose. Industrial \& Engineering Chemistry Research, 45(19) 6477-6482 (2006)

32. Marini, M., Bondi, M., Iseppi, R., Toselli, M. and Pilati, F., Preparation and Antibacterial Activity of Hybrid Materials Containing Quaternary Ammonium Salts Via Sol-Gel Process. European Polymer Journal, 43(8) 3621-3628 (2007)

33. Caillier, L., de Givenchy, E.T., Levy, R., Vandenberghe, Y., Géribaldi, S. and Guittard, F., Synthesis and Antimicrobial Properties of Polymerizable Quaternary Ammoniums. European Journal of Medicinal Chemistry, 44(8) 3201-3208 (2009)

34. Kim, H.W., Kim, B.R. and Rhee, Y.H., Imparting Durable Antimicrobial Properties to Cotton Fabrics Using Alginate-Quaternary Ammonium Complex Nanoparticles. Carbohydrate Polymers, 79(4) 1057-1062 (2010)

35. Li, J., Zhang, Q., Wang, Y., Zhang, W. and Li, T., Synthesis and Properties of Organosilicon Quaternary Salts Surfactants. Journal of Surfactants and Detergents, 15(3) 339-344 (2012)

36. Yu, M., Gu, G., Meng, W.-D. and Qing, F.-L., Superhydrophobic Cotton Fabric Coating Based on a Complex Layer of Silica Nanoparticles and
Perfluorooctylated Quaternary Ammonium Silane Coupling Agent. Applied Surface Science, 253(7) 3669-3673 (2007)

37. Chojnowski, J., Fortuniak, W., Rościszewski, P., Werel, W., Łukasiak, J., Kamysz, W. and Hałasa, R., Polysilsesquioxanes and Oligosilsesquioxanes Substituted by Alkylammonium Salts as Antibacterial Biocides. Journal of Inorganic and Organometallic Polymers and Materials, 16(3) 219-230 (2006)

38. Majumdar, P., He, J., Lee, E., Kallam, A., Gubbins, N., Stafslien, S.J., Daniels, J. and Chisholm, B.J., Antimicrobial Activity of Polysiloxane Coatings Containing Quaternary AmmoniumFunctionalized Polyhedral Oligomeric Silsesquioxane. Journal of Coatings Technology and Research, 7(4) 455-467 (2009)

39. Carteau, D., Vallée-Réhel, K., Linossier, I., Quiniou, F., Davy, R., Compère, C., Delbury, M. and Faÿ, F., Development of Environmentally Friendly Antifouling Paints Using Biodegradable Polymer and Lower Toxic Substances. Progress in Organic Coatings, 77(2) 485-493 (2014)

40. Majumdar, P., Lee, E., Patel, N., Stafslien, S.J., Daniels, J. and Chisholm, B.J., Development of Environmentally Friendly, Antifouling Coatings Based on Tethered Quaternary Ammonium Salts in a Crosslinked Polydimethylsiloxane Matrix. Journal of Coatings Technology and Research, 5(4) 405-417 (2008)

41. Mizerska, U., Fortuniak, W., Chojnowski, J., Hałasa, R., Konopacka, A. and Werel, W., Polysiloxane Cationic Biocides with Imidazolium Salt (Ims) Groups, Synthesis and Antibacterial Properties. European Polymer Journal, 45(3) 779-787 (2009)

42. Majumdar, P., Lee, E., Gubbins, N., Stafslien, S.J., Daniels, J., Thorson, C.J. and Chisholm, B.J., Synthesis and Antimicrobial Activity of Quaternary Ammonium-Functionalized Poss (Q-Poss) and Polysiloxane Coatings Containing Q-Poss. Polymer, 50(5) 1124-1133 (2009)

43. Mahltig, B., Fiedler, D. and Böttcher, H., Antimicrobial Sol-Gel Coatings. Journal of SolGel Science and Technology, 32(1) 219-222 (2004)

44. Wang, X. and Wang, C., The Antibacterial Finish of Cotton Via Sols Containing Quaternary Ammonium Salts. Journal of Sol-Gel Science and Technology, 50(1) 15-21 (2009)

J.Text.Color. Polym. Sci., Vol., No.(2019) 
45. Mohamed, A.L. and Hassabo, A.G., Flame Retardant of Cellulosic Materials and Their Composites, in Flame Retardants, P.M. Visakh and Y. Arao, Editors Springer International Publishing. p. 247-314 (2015)

46. Hribernik, S., Smole, M.S., Kleinschek, K.S., Bele, M., Jamnik, J. and Gaberscek, M., Flame Retardant Activity of Sio2-Coated Regenerated Cellulose Fibres. Polymer Degradation and Stability, 92(11) 1957-1965 (2007)

47. Alongi, J., Ciobanu, M., Tata, J., Carosio, F. and Malucelli, G., Thermal Stability and Flame Retardancy of Polyester, Cotton, and Relative Blend Textile Fabrics Subjected to Sol-Gel Treatments. Journal of Applied Polymer Science, 119(4) 1961-1969 (2011)

48. Alongi, J., Ciobanu, M. and Malucelli, G., Sol-Gel Treatments for Enhancing Flame Retardancy and Thermal Stability of Cotton Fabrics: Optimisation of the Process and Evaluation of the Durability. Cellulose, 18(1) 167-177 (2010)

49. Alongi, J. and Malucelli, G., Thermal Degradation of Cellulose and Cellulosic Substrates, in Reactions and Mechanisms in Thermal Analysis of Advanced Materials John Wiley \& Sons, Inc. p. 301-332 (2015)

50. Alongi, J., Ciobanu, M. and Malucelli, G., Sol-Gel Treatments on Cotton Fabrics for Improving Thermal and Flame Stability: Effect of the Structure of the Alkoxysilane Precursor. Carbohydrate Polymers, 87(1) 627-635 (2012)

51. Alongi, J., Ciobanu, M. and Malucelli, G., Thermal Stability, Flame Retardancy and Mechanical Properties of Cotton Fabrics Treated with Inorganic Coatings Synthesized through SolGel Processes. Carbohydrate Polymers, 87(3) 2093-2099 (2012)

52. Alongi, J. and Malucelli, G., Thermal Stability, Flame Retardancy and Abrasion Resistance of Cotton and Cotton-Linen Blends Treated by SolGel Silica Coatings Containing Alumina Microor Nano-Particles. Polymer Degradation and Stability, 98(8) 1428-1438 (2013)

53. Brzeziński, S., Kowalczyk, D., Borak, B., Jasiorski, M. and Tracz, A., Applying the Sol-Gel Method to the Deposition of Nanocoats on Textiles to Improve Their Abrasion Resistance. Journal of Applied Polymer Science, 125(4) 3058-3067 (2012)

J.Text.Color. Polym. Sci., Vol. , No. (2019)
54. Brancatelli, G., Colleoni, C., Massafra, M.R. and Rosace, G., Effect of Hybrid Phosphorus-Doped Silica Thin Films Produced by Sol-Gel Method on the Thermal Behavior of Cotton Fabrics. Polymer Degradation and Stability, 96(4) 483-490 (2011)

55. Alongi, J., Colleoni, C., Rosace, G. and Malucelli, G., Thermal and Fire Stability of Cotton Fabrics Coated with Hybrid Phosphorus-Doped Silica Films. Journal of Thermal Analysis and Calorimetry, 110(3) 1207-1216 (2012)

56. Ferrero, F. and Periolatto, M., Modification of Surface Energy and Wetting of Textile Fibers, in Wetting and Wettability, M. Aliofkhazraei, Editor InTech (2015)

57. Pilotek, S. and Schmidt, H.K., Wettability of Microstructured Hydrophobic Sol-Gel Coatings. Diary of Sol-Gel Science and Technology, 26(13) 789-792 (2003)

58. Periolatto, M., Ferrero, F., Montarsolo, A. and Mossotti, R., Hydrorepellent Finishing of Cotton Fabrics by Chemically Modified Teos Based Nanosol. Cellulose, 20(1) 355-364 (2013)

59. Wang, H., Fang, J., Cheng, T., Ding, J., Qu, L., Dai, L., Wang, X. and Lin, T., OneStep Coating of Fluoro-Containing Silica Nanoparticles for Universal Generation of Surface Superhydrophobicity. Chemical Communications, (7) $877-879$ (2008)

60. 60. Li, S., Xie, H., Zhang, S. and Wang, X., Facile Transformation of Hydrophilic Cellulose into Superhydrophobic Cellulose. Chemical Communications, (46) 4857-4859 (2007)

61. Daoud, W.A., Xin, J.H. and Tao, X., Superhydrophobic Silica Nanocomposite Coating by a Low-Temperature Process. Journal of the American Ceramic Society, 87(9) 1782-1784 (2004)

62. Hoefnagels, H.F., Wu, D., de With, G. and Ming, W., Biomimetic Superhydrophobic and Highly Oleophobic Cotton Textiles. Langmuir, 23(26) 13158-13163 (2007)

63. Reuß, M. and Ratke, L., Subcritically Dried Rf-Aerogels Catalysed by Hydrochloric Acid. Journal of Sol-Gel Science and Technology, 47(1) 74-80 (2008)

64. Vilčnik, A., Jerman, I., Šurca Vuk, A., Koželj, M., Orel, B., Tomšič, B., Simončič, B. and Kovač, J., Structural Properties and Antibacterial Effects of Hydrophobic and Oleophobic Sol-Gel Coatings 
for Cotton Fabrics. Langmuir, 25(10) 5869-5880 (2009)

65. Liang, J., Zhou, Y., Jiang, G., Wang, R., Wang, X., $\mathrm{Hu}, \mathrm{R}$. and Xi, X., Transformation of Hydrophilic Cotton Fabrics into Superhydrophobic Surfaces for Oil/Water Separation. The Journal of The Textile Institute, 104(3) 305-311 (2013)

66. Islam, M.M. and Huiyu, J., Synthesis of Silicone Oil and Application on Knit and Woven Cotton Dyed Fabrics. International Journal of Scientific \& Engineering Research, 6(12) 2015375 (2015)

67. Stadrto, K. and Schka, B., Softeners in the Textile Finishing Industry. Colourage, (1) 53-58 (1997)

68. Chattopadhyay, D.P. and Vyas, D.D., Effect of Silicone Nano-Emulsion Softener on Physical Properties of Cotton Fabric. Indian Journal of Fibre \& Textile Research, 35(2) 68-71 (2010)

69. Brunon, C., Bessueille, F., Grossiord, C., Chadeau, E., Oulahal, N., Darroux, C., Ferreira, I., Bourgeois, M., Simon, F., Rimbault, F., Yu, C. and Leonard, D., Tof-Sims and Xps Characterization of Antimicrobial Textiles for the Food Processing Industry. Surface and Interface Analysis, 43(1-2) $604-608$ (2011)

70. Vilčnik, A., Jerman, I., Šurca Vuk, A., Koželj, M., Orel, B., Tomšič, B., Simončič, B. and Kovač, J., Structural Properties and Antibacterial Effects of Hydrophobic and Oleophobic Sol-Gel Coatings for Cotton Fabrics. Langmuir, 25(10) 5869-5880 (2009)

71. Fleming, O.S., Stepanek, F. and Kazarian, S.G., Dye Diffusion in Polymer Films Subjected to Supercritical Co2: Confocal Raman Microscopy and Modelling. Macromolecular Chemistry and Physics, 206(11) 1077-1083 (2005)

72. Vyörykkä, J., Halttunen, M., Iitti, H., Tenhunen, J., Vuorinen, T. and Stenius, P., Characteristics of Immersion Sampling Technique in Confocal Raman Depth Profiling. Applied Spectroscopy, 56(6) 776 - 782 (2002)

73. Reinecke, H., Spells, S.J., Sacristán, J., Yarwood, J. and Mijangos, C., Confocal Raman Depth Profiling of Surface-Modified Polymer Films: Effects of Sample Refractive Index. Applied Spectroscopy, 55(12) 1660 - 1664 (2001)

74. Baldwin, K.J. and Batchelder, D.N., Confocal Raman Microspectroscopy through a Planar Interface. Applied Spectroscopy, 55(12) 517 - 524 (2001)
75. Jurdana, L.E., Ghiggino, K.P., Nugent, K.W. and Leaver, I.H., Confocal Laser Raman Microprobe Studies of Keratin Fibers. Textile Research Journal, 65(10) 593-600 (1995)

76. Kelemen, J., Moss, S. and Glitsch, S., AzoHydrazone Tautomerism in Azo Dyes. Iv. Colour and Tautomeric Structure of Adsorbed 1-Phenylazo-2-Naphthylamine and 1-Phenylazo2-Naphthol Dyes. Dyes and Pigments, 5(2) 83108 (1984)

77. Kulshreshtha, A.K. and Dweltz, N.E., Analysis of Flame-Retardant Finishes on Textiles Using Laser-Raman Spectroscopy. Ind. J. Textile Res., 6 135 - 138 (1981)

78. Mohamed, A.L., Er-Rafik, M. and Moller, M., Suitability of Confocal Raman Microscopy for Monitoring the Penetration of Pdms Compounds into Cotton Fibres. Carbohydrate Polymers, 96(1) 305-313 (2013)

79. Mohamed, A.L., Er-Rafik, M. and Moller, M., Supercritical Carbon Dioxide Assisted Silicon Based Finishing of Cellulosic Fabric: A Novel Approach. Carbohydrate Polymers, 98(1) 10951107 (2013)

80. Scientific Committee on Consumer Products, Opinion on Octamethylcyclotetrasiloxane (D4) Cyclomethicone (Inci Name), (2005)

81. Klykken, P.C., Galbraith, T.W., Kolesar, G.B., Jean, P.A., Woolhiser, M.R., Elwell, M.R., Burns-Naas, L.A., Mast, R.W., McCay, J.A., White Jr, K.L. and Munson, A.E., Toxicology and Humoral Immunity Assessment of Octamethylcyclotetrasiloxane (D4) Following a 28-Day Whole Body Vapor Inhalation Exposure in Fischer 344 Rats. Drug and Chemical Toxicology, 22(4) 655-677 (1999)

82. McKim, J.M., Choudhuri, S., Wilga, P.C., Madan, A., Burns-Naas, L.A., Gallavan, R.H., Mast, R.W., Naas, D.J., Parkinson, A. and Meeks, R.G., Induction of Hepatic Xenobiotic Metabolizing Enzymes in Female Fischer-344 Rats Following Repeated Inhalation Exposure to Decamethylcyclopentasiloxane (D5). Toxicological Sciences, 50(1) 10-19 (1999)

83. Reddy, M.B., Looney, R.J., Utell, M.J., Plotzke, K.P. and Andersen, M.E., Modeling of Human Dermal Absorption of Octamethylcyclotetrasiloxane (D4) and Decamethylcyclopentasiloxane (D5). Toxicological Sciences, 99(2) 422-431 (2007)

84. BIBRA working group, Report for Toxicity 
Profile, Polydimethylsiloxane, (1991)

85. Graiver, D., Farminer, K.W. and Narayan, R., A Review of the Fate and Effects of Silicones in the Environment. Journal of Polymers and the Environment, 11(4) 129-136 (2003)

86. Watts, R.J., Kong, S., Haling, C.S., Gearhart, L., Frye, C.L. and Vigon, B.W., Fate and Effects of Polydimethylsiloxanes on Pilot and Bench-Top Activated Sludge Reactors and Anaerobic/Aerobic Digesters. Water Research, 29(10) 2405-2411 (1995)

87. Lehmann, R.G., Varaprath, S., Annelin, R.B. and Arndt, J.L., Degradation of Silicone Polymer in a Variety of Soils. Environmental Toxicology and Chemistry, 14(8) 1299-1305 (1995)

88. Lehmann, R.G., Varaprath, S. and Frye, C.L., Degradation of Silicone Polymers in Soil. Environmental Toxicology and Chemistry, 13(7) 1061-1064 (1994)

89. Fendinger, N.J., McAvoy, D.C., Eckhoff, W.S. and Price, B.B., Environmental Occurrence of Polydimethylsiloxane. Environmental Science \& Technology, 31(5) 1555-1563 (1997)

90.

91.
(Received 23/ 10 /2019;

accepted 4 / 12 /2019)

J.Text.Color. Polym. Sci., Vol. , No. (2019) 


$$
\begin{aligned}
& \text { در اسة مرجعية للمو اد القائمة على السيليكون وتطبيقاتها الوظيفية علي الأقمشة السليلوزية } \\
& \text { * أحمد حسبو وأمينة محمد العزمب }
\end{aligned}
$$

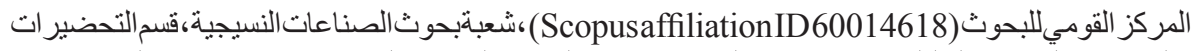

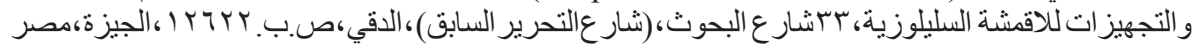

\footnotetext{
نحن تستخدم المواد القائمة على السيليكون في الملابس و الصناعة. كما في حالة المو اد اللاصقة ، يتم استخدام

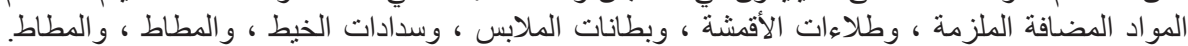

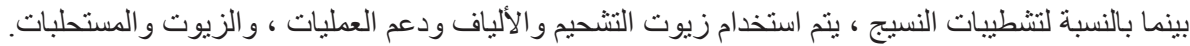

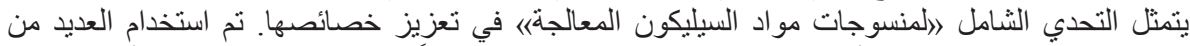

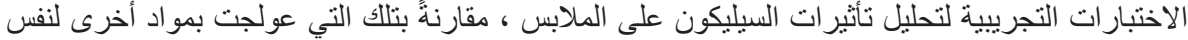

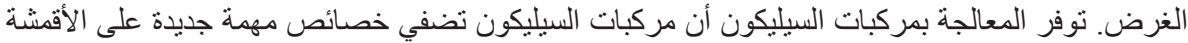

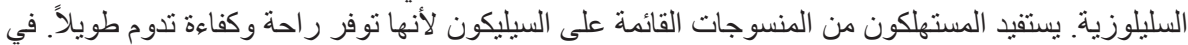

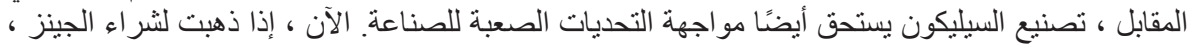

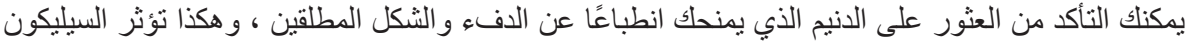

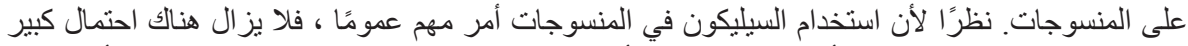

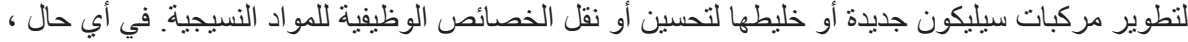
فإن عمليات البحث في المستقبل هي على نطاق واسع للسيليكون المعالجة النسيج. هناك حتى القترح الاستخدامات الكيات الممكنة في المجال الطبي العلاجي.
} 